\title{
EL PUNTO DE ENCUENTRO ENTRE LA TEORÍA PENAL Y LA TEORÍA DEMOCRÁTICA DE CARLOS NINO
}

\author{
Roberto Gargarella \\ Universidad de Buenos Aires - Universidad Torcuato Di Tella - CONICET
}

\section{Resumen}

En el trabajo, intento repensar la teoría penal de Carlos Nino, desarrollada durante sus estudios doctorales y posdoctorales, a la luz de su teoría de la democracia deliberativa, elaborada desde los años 80. Nino no tuvo la oportunidad de revisar plenamente sus estudios penales en la materia, luego de desarrollar su teoría de la democracia y este artículo se propone entonces dar algunos primeros pasos en esa dirección y explorar algunas posibles implicaciones de dicha tarea.

PALABRAS CLAVE: C. S. Nino; Teoría penal; Castigo; Democracia; Igualdad; Amnistías; Derechos humanos.

\begin{abstract}
In this work, I try to re-think Carlos Nino's theory about the Criminal Law, which he developed while he pursued his doctoral and post-doctoral studies, under the light of his deliberative theory of democracy, which he elaborated since the 1980s. Nino had no chance to develop this revision, so this article suggests ways to begin with this required re-elaboration.
\end{abstract}

KEY WORDS: C. S. Nino; Criminal Law Theory; Punishment; Democracy; Equality; Amnesties; Human Rights.

En el año 1977, el profesor Carlos Nino (1943-1993) obtuvo su doctorado en leyes en la Universidad de Oxford, bajo la dirección de John Finnis y Tony Honoré. La tesis se titulaba Towards a general strategy for criminal law adjudication, y estuvo marcada, como todos sus escritos, acentuadamente y desde entonces, por una filosofía de impronta liberal, claramente asociada al ambiente académico que conociera en Inglaterra. Sin embargo, todos los trabajos producidos por él en la última larga década de su vida, mostraron otra impronta dominante, relacionada con sus estudios en torno a la democracia, que comenzaron a tomar protagonismo a través de investigaciones desarrolladas al calor de la transición democrática argentina que comenzara en 1983. Esta nueva línea de reflexión llevó a Nino a rever algunas de las conclusiones a las que llegara en su etapa más joven, por ejemplo en lo referido a la naturaleza u origen 
de los derechos, o en relación con el papel de los jueces y el control de constitucionalidad. Notablemente, sin embargo, los estudios que realizara en materia penal, en aquella etapa temprana distinguida por su liberalismo oxoniense, no fueron modificados de modo significativo por la llegada del "vendaval democrático" que definiría sus trabajos, claramente y al menos, desde 1982. La teoría de la pena que él desarrollara en Inglaterra - la que él presentara como una teoría consensual de la pena- quedaría así, fundamentalmente (aunque no por completo) "incontaminada" por sus estudios de teoría democrática, relacionados de modo especial con su concepción deliberativa/epistémica de la democracia (véase, en particular, Nino 1984, 1996; Elster 1998; Bohman 1996). ${ }^{1}$ En este trabajo, por lo dicho, quisiera ocuparme de esa conexión poco explorada por Nino, y ver de qué modo sus últimos trabajos en torno a la teoría democrática podrían impactar sobre sus primeros trabajos en materia penal. ${ }^{2}$ En particular, me concentraré aquí en una cuestión, relacionada con el origen democrático y la validez de las normas penales. ${ }^{3}$

Mi análisis tomará como punto de partida el caso que representara el primer, crucial, y casi único punto de encuentro entre la vieja teoría penal y la nueva teoría democrática, dentro de la obra de Carlos Nino: me refiero a los aportes que hiciera en torno a la validez del derecho (Nino 1985), a la luz del grave debate que se diera en la Argentina en torno a cómo tratar la ley de autoamnistía que impulsara, en 1983, el último presidente militar que gobernó el país.

1 La "teoría consensual" que él elaborara, marcada por el liberalismo, se caracterizaría por una preocupación muy particular por los rasgos distributivos de la pena; y aparecería moldeada y limitada a la vez por principios como los de autonomía, inviolabilidad y dignidad de la persona, que Nino defendería con detalle, más adelante, en Ética y derechos humanos (1984).

${ }^{2}$ Un primer intento importante de conectar ambas esferas del trabajo de Nino, en de Greiff (2002).

${ }^{3}$ Durante la última década de su vida, Nino concentró sus trabajos principales en otras áreas de la teoría y el derecho (incluyendo, de modo especial, al derecho constitucional, pero también, por ejemplo, al derecho de familia, a la filosofía política, a la sociología política y a la teoría democrática). En esta última etapa, él no volvería a ocuparse, prácticamente, de los asuntos penales. De todos modos, en uno de sus últimos libros -Radical Evil on Trial-Nino se dedicó a repensar críticamente los juicios a la Junta Militar promovidos durante el gobierno democrático de Ricardo Alfonsín (juicios en cuyo diseño Nino estuviera involucrado de modo directo), pero manteniendo tanto a su teoría de la pena como a su teoría democrática básicamente separadas entre sí, como ocupando esferas diferentes. 


\section{Democracia deliberativa y castigo: el debate en torno a la autoamnistía militar}

La discusión sobre la validez de la ley de autoamnistía militar representa un llamativo punto de inflexión en la biografía académica de Carlos Nino que coincide con un momento fundamental (tiempo de "renovación y cambio") en la historia del país. ${ }^{4}$ En lo que hace a la biografía de Nino, cabe recordar que él había vuelto hacía poco al país, luego de terminada su tesis doctoral sobre teoría penal en Inglaterra. Llegado a la Argentina, Nino se encontró con la euforia propia de la vuelta a la democracia, y prontamente se vinculó a la política de la mano del líder de la Unión Cívica Radical que llegaría en esas elecciones a la presidencia del país. Como asesor del futuro presidente Alfonsín, Nino se involucró de lleno en una diversidad de debates de primera importancia, relacionados con la recuperación y reconstrucción democrática en el país. No casualmente, el eje de sus estudios académicos empezó a virar, entonces, desde la esfera penal a la teoría democrática y los fundamentos del constitucionalismo. Como se puede advertir, este cambio que se daba en la orientación de los trabajos académicos de Nino, acompañaban al quiebre que se estaba terminando de afirmar, en la política del país, entre el autoritarismo político y la vida democrática.

Ese momento de cambio - ese punto de quiebre- encuentra una expresión de primerísima importancia en la discusión en torno a la autoamnistía militar. La pregunta era entonces qué es lo que debía hacer el nuevo gobierno democrático en relación con la última normativa militar, que impedía toda investigación sobre las atrocidades cometidas por los militares, cuando la amplia mayoría del país consideraba que debía haber "juicio y castigo" para los culpables de las masivas y gravísimas violaciones a los derechos humanos cometidos durante los tiempos de la dictadura (1976-1983). Para ilustrar la relevancia pública que adquiriría la cuestión, baste señalar que dicha norma de autoamnistía sería finalmente invalidada por el nuevo Congreso democrático que, simbólicamente, convertiría a dicho acto en la primera ley dictada por la nueva democracia. Pues bien, ese primer acto de la nueva democracia argentina representó el momento fundamental de cambio en los estudios de Nino y pasó a constituirse en el gran punto de encuentro entre la vieja teoría penal y la nueva teoría democrática.

\footnotetext{
"Valga aclarar que "renovación y cambio" era el lema de la facción del partido radical a la que Nino adhería, y que en ese momento ganara la presidencia democrática del país, bajo la dirección y el liderazgo del Dr. Raúl Alfonsín.
} 
Conviene repasar brevemente los antecedentes propios de la discusión de esta norma. Ante todo, corresponde recordar que la norma que está aquí en juego es la ley 22.934 o de autoamnistía, dictada bajo el gobierno del dictador General Bignone, el 23 de septiembre de 1983, a semanas de la asunción del nuevo gobierno democrático argentino. La norma en cuestión tuvo como objetivo declarado el de "pacificar al país" y asegurar la "reconciliación social" y estuvo dirigida a perdonar todos los actos "subversivos o antisubversivos" cometidos entre mayo de 1973 y junio de 1982, cubriendo a los responsables directos de los crímenes en cuestión, y a quienes habían colaborado con ellos.

En los tiempos previos a la primera elección de la restauración democrática, uno de los dos partidos políticos más importantes del país -el partido peronista, encabezado entonces por el jurista Ítalo Luderpropuso simplemente reconocer la validez de aquella norma de autoamnistía, como si la democracia no contara con herramientas jurídicas apropiadas para enfrentarla. La combinación del art. 2 del Código Penal (ley más favorable) y el 18 de la Constitución (no irretroactividad de las normas penales) se aliaban para que juristas como Luder, y partidos políticos como el que él encabezaba, arribaran a tal conclusión. Desde las cercanías del segundo partido político más influyente en esos años (el radicalismo) se ensayaron mientras tanto algunas respuestas jurídicas alternativas. Genaro Carrió, por ejemplo (quien presidiría la Corte Suprema desde 1983), impulsó una embestida contra la autoamnistía militar, en base al artículo 29 de la Constitución, que impedía la concesión de facultades extraordinarias al Poder Ejecutivo. Nino, en cambio, favoreció otro acercamiento al problema, que combinaba su crítica al positivismo jurídico (en la vertiente extrema que él llamaba "positivísimo ideológico"), y su embrionario acercamiento "epistémico" a la democracia -una posición que dejaría en claro en un temprano artículo aparecido en el diario jurídico La Ley (Nino 1983a, y en general Nino 1993, pp. 64-66). Su idea era, por un lado, que había una típica falacia naturalista en la idea de que la fuerza normativa de una disposición legal podía derivarse de cuestiones fácticas, como las vinculadas con el poder coercitivo concentrado en las manos de quien la había dictado; y por otro, que solo las normas surgidas de un procedimiento de debate democrático gozaban de una presunción de aceptabilidad moral $\mathrm{y}$, finalmente, de una presunción de validez jurídica. Nino desarrollaría estas ideas, de modo especial, en su libro de 1985 dedicado a la validez del derecho (Nino 1985).

En sus trabajos más detallados sobre la democracia (que aparecen consolidados en Nino 1984), Nino precisó los contornos de su acercamiento "epistémico" a la democracia, dejando en claro que un proceso de discusión 
colectiva ampliamente inclusivo, maximizaba como ningún otro procedimiento alternativo la posibilidad de tomar decisiones imparciales, esto es decir, decisiones respetuosas de los puntos de vista de todos los involucrados (esto así, aclararía Nino, en cuestiones de moral intersubjetiva, aunque no en cuestiones de moral privada). Su visión sobre este punto, en cierta manera, retomaba el principio distintivo de la concepción habermasiana de la democracia referido a la discusión entre todos los potencialmente afectados (Habermas 1996)

Para Nino, un proceso de discusión con las características citadas favorecía la imparcialidad al asentarse en el intercambio de razones; al alentar la circulación de información relevante; y al ayudar a los procesos de mutua corrección. En definitiva, lo que vemos aquí es de qué modo, la necesidad de reflexionar sobre la validez de la ley de autoamnistía había llevado a Nino a reflexionar sobre cuestiones filosóficas relativas a la validez del derecho y a precisar a partir de allí los contornos de su teoría democrática.

\section{La anulación de la ley de autoamnistía argentina y la distinción con la amnistía uruguaya}

Tenemos ya delineados los primeros rasgos de la reflexión inaugurada por Nino sobre el origen de las normas y el derecho penal. La idea es que la validez de las normas (penales en este caso) resulta socavada en la medida en que pretende asentarse sobre la mera fuerza o capacidad coercitiva ejercida por quien las dicta (una cuestión fundamental, que venía a disputar lo que era la posición dominante dentro de la jurisprudencia y doctrina nacionales, forjada en torno a la inaceptable doctrina de facto). Para Nino, la validez de las normas se veía favorecida y reforzada por procesos de discusión como los que resultaban propios de un sistema democrático. El proceso de creación de la ley aparecía así conectado con la fuerza normativa de su contenido. Y aunque, en principio, teóricamente, una norma podía terminar siendo justa o injusta con independencia de su proceso de creación, Nino diría que el proceso democrático nos confiere razones especiales para considerar que el contenido de la norma es justo. El debate democrático ayudaba entonces a que las normas así generadas cuenten con una fuerte (aunque rebatible) presunción de validez.

La muy dura batalla jurídica en torno a la validez o no de la ley de autoamnistía, concluyó con la nulificación ex nihilo de aquella, hecha por el Congreso y basada en una nueva doctrina en torno a las normas de facto, en buena medida hija de las reflexiones de Carlos Nino. La 
anulación de la ley de autoamnistía pasó a ser entonces la primera ley aprobada por el nuevo Congreso democrático reinstalado en 1983 (ley 23.040). Terminada dicha batalla, Nino apartó del centro de sus reflexiones a las cuestiones relacionadas con el derecho penal, para -en sintonía con los nuevos debates que instalaba la naciente democraciacomenzar a trabajar sobre cuestiones constitucionales más directas, como las relacionadas con la reforma constitucional, la reforma de la Justicia, o la Ley de Radiodifusión. Solo ocasionalmente, y de modo más bien excepcional, Nino volvería a desarrollar sus puntos de vista sobre la materia (y, en particular, sobre las conexiones entre origen democrático de las normas y derecho penal).

Llegados a este punto, es interesante resaltar que, al argumentar a favor de la anulación de la ley de autoamnistía, Nino no trazó una distinción categórica entre normas válidas y no válidas. Más bien, Nino se ocupó de presentar un ideal regulativo -al que denominaba el discurso moral ideal, de pleno acuerdo entre todos los afectados- que nos permitía pensar en gradaciones o presunciones de validez. Las normas democráticas, en general, gozaban de una fuerte presunción de validez, mientras que las normas surgidas en una dictadura, no. Pero otra vez, la distinción por él propuesta no debía ser reducida al trazado de una línea gruesa entre autoritarismo y democracia. No: la validez de una norma podía ser mayor o menor conforme (pongamos) a los niveles de discusión e inclusión propios de la misma, ya sea que hablemos de regímenes autoritarios o democráticos. Por supuesto, y en general, las normas surgidas en una dictadura van a gozar de una bajísima presunción de validez - cercana a 0 - debido a que (y en la medida en que) en tales condiciones se extreman la falta de discusión y de inclusión social, requisitos esenciales para maximizar la imparcialidad de una ley. Las normas democráticas, mientras tanto, van a gozar en principio de la presunción de validez de la que no gozan las normas autoritarias, que por lo demás va a aumentar o disminuir conforme -otra vez- a los ingredientes de (digamos) inclusión e inclusión social de que estén rodeadas. Lo que me interesa destacar, entonces, es de qué modo Nino abría la puerta para la discusión en torno a los grados de validez de las normas.

Afortunadamente, contamos con otro ejemplo especialmente pertinente para apoyar la discusión que aquí estamos dando: el caso de la Ley de Caducidad (o amnistía) aprobada en Uruguay, por el nuevo Congreso democrático, al final de la dictadura que también azolara a dicho país. La amnistía uruguaya, conforme veremos, tuvo un origen, y por tanto unas condiciones de validez, completamente diferentes de la autoaministía argentina. No se trata, simplemente, de que ley del caso no era una ley 
de autoamnistía (dato relevante, pero que estimamos secundario frente al siguiente) sino, sobre todo, de que se trata de una amnistía aprobada y ratificada popularmente, en condiciones democráticas excepcionales (a diferencia de las condiciones excluyentes que distinguieron a la amnistía argentina).

En efecto, la así llamada "Ley de Caducidad de la Pretensión Punitiva" fue promulgada el 22 de diciembre de 1986 por el Congreso democrático de Uruguay. Poco después, la misma fue ratificada en procesos de consulta directa a la ciudadanía uruguaya en dos oportunidades. La primera vez, a través de un referéndum realizado en abril de 1989, en donde la norma fue sostenida por el 58\% de los votos. Más tarde, y ya con el Frente Amplio en el poder (agrupación que no había propuesto derogar ni anular la Ley en cuestión), la ciudadanía juntó las firmas necesarias para volver a poner bajo consideración popular a la norma objetada. El plebiscito se terminó realizando el 25 de octubre del 2009, y los votos a favor de la invalidación de la Ley llegaron aproximadamente al $48 \%$, con lo cual la misma mantuvo su vigencia.

Nos encontramos entonces con una amnistía que, a diferencia de la aprobada en la Argentina por la dictadura, fue el producto de condiciones democráticas verdaderamente excepcionales, muy poco habituales para cualquier norma aprobada en democracia, en cualquier país de la región, a la largo de toda su historia. La norma, en efecto, resultó discutida popularmente, en los diarios, en las calles, a través de manifestaciones recurrentes, y por todos los poderes del Estado, en varias oportunidades. ¿Qué decir, entonces, frente a la validez de dicha decisión colectiva de perdonar? Y, más precisamente para el marco de esta investigación: ¿qué podría decir una teoría como la de Nino, frente a una norma semejante?

Desgraciadamente, Nino falleció antes de que se completase todo el proceso de discusión y ratificación de la normativa uruguaya. Por suerte, en cambio, Nino supo de la aprobación de dicha norma por el Congreso uruguayo y supo también del resultado obtenido luego del primer referéndum. Por ello mismo, y reconociendo el valor distintivo de lo que ocurriera en Uruguay, le dedicó algunos breves pero sugerentes párrafos en su libro Radical Evil on Trial. En dichos párrafos, Nino dejó trascender, por un lado, su incomodidad frente a la norma, pero asimismo, y mostrando la genuina honestidad de su teoría, Nino hizo explícito reconocimiento del carácter especial de la misma, y el riesgo de "elitismo epistémico" propio de quienes, sencillamente, impugnaban su validez. Escribió Nino entonces (luego de referirse a otros procesos de justicia transicional, como los de Alemania y Grecia): 
El caso más difícil es el de Uruguay, donde un acto democrático -un referendo realizado luego de la transición- garantizó la amnistía a los violadores de derechos humanos. Cuando el proceso democrático resulta en un balance de derechos e intereses que apunta hacia el perdón, se presume, aunque siempre sea posible el disenso, que este curso de acción es el correcto. Esto se sigue de una justificación del castigo que no descansa en la retribución, sino en razones prudenciales de protección social y del rechazo de una postura epistémica elitista acerca de cuándo es que las precondiciones del castigo correcto se encuentran satisfechas (Nino 1996, pp. 163-164).

Es decir, a pesar de la perplejidad que le producía el caso y la dificultad que en principio le generaba su tratamiento, Nino tenía claro - contra una vasta mayoría de sus colegas- que esa norma no podía considerarse, simplemente, como norma inválida, por el hecho de generar un resultado con el que muchos podíamos estar fuertemente en desacuerdo. Lamentablemente, sin embargo, dicha norma fue rápida y superficialmente considerada inválida por la Corte Interamericana de Derechos Humanos, en un fallo (Gelman) de febrero del 2011 que de modo sorprendente descartó todo valor al componente democrático de la norma cuestionada, al que consideró entonces como un dato simplemente "formal" y finalmente irrelevante. La Corte IDH, entonces, terminó por equiparar y poner a la misma altura a la vergonzante ley de amnistía dictada por la dictadura argentina, y a la Ley de Caducidad uruguaya, aprobada en condiciones democráticas únicas, difícilmente repetibles en la historia de la región (Gargarella 2013).

Conviene retomar, al menos brevemente, lo que se dijera en el fallo Gelman, de la Corte IDH contra la normativa uruguaya, dado que el citado fallo recuperó, de modo sintético, la esencia del argumento hostil-a-lademocracia que ha distinguido siempre, y sigue distinguiendo aún hoy, a la doctrina penal latina.

La línea argumental recorrida por la Corte IDH fue la habitual en estos casos: i) las cuestiones democráticas no tienen nada que ver con las cuestiones sobre derechos; ii) cualquier intervención democrática sobre temas de derechos debe ser rechazada y atacada (invalidada); y iii) son los jueces los únicos que están realmente capacitados para entender qué es lo que significan los derechos, e institucionalmente designados para defenderlos. En este sentido, la Corte IDH reivindicó e hizo propios muchos de los dichos de la Corte Suprema Uruguaya en el caso Nibia Sabalsagaray Curutchet, en la que aquella se ocupara de la Ley de Caducidad. La Corte de Uruguay, típicamente, había apoyado su decisión 
en posiciones hostiles a la democracia penal, como la del iusfilósofo italiano Luigi Ferrajoli (autoridad de referencia permanente de la jurisprudencia latinoamericana en cuestiones relacionadas con el castigo penal). Junto al italiano, la Corte uruguaya había suscrito la idea conforme a la cual existe una esfera de lo no decidible ajena a cualquier interferencia democrática, y a cargo del resguardo judicial. Citando directamente a Ferrajoli, el tribunal uruguayo sostuvo:

las cuestiones pertenecientes a lo que he llamado 'esfera de lo decidible', los derechos fundamentales están sustraídos a la esfera de la decisión política y pertenecen a la que he llamado 'esfera de lo no decidible' [...] Siempre que se quiere tutelar un derecho como fundamental se lo sustrae a la política, es decir, a los poderes de la mayoría [...] como derecho inviolable, indisponible e inalienable. Ninguna mayoría, ni siquiera por unanimidad, puede decidir su abolición o reducción. ${ }^{5}$

Posturas como las de la Corte IDH en Gelman, o la de la Corte del Uruguay en Nibia Sabalsagaray, ilustran bien cuál es el modo de pensar dominante dentro de la doctrina penal contemporánea, al menos en el mundo latino. Dicha forma de pensar, que hace centro en el papel de los jueces y desconfía de cualquier "interferencia" democrática en materia penal, se encuentra en las antípodas de la postura que elaborara y dejara sugerida Nino a través de sus escritos. En efecto, y con el correr de los años, para Nino estuvo cada vez más claro que los derechos no podían ser entendidos como "derechos naturales" autoevidentes (tal como los entendiera John Locke y la tradicional doctrina liberal que se elaborara a partir de los escritos del pensador inglés); que la esfera de la democracia y la esfera de los derechos se encontraban obviamente vinculadas entre sí; y que la discusión en torno al significado y alcance de los derechos no podía quedar atrapada dentro de las estrechas paredes de la decisión judicial.

Por lo dicho, la plebiscitada decisión uruguaya resulta de especial interés para pensar la teoría de Nino sobre la validez de las leyes: ella -a diferencia de la autoamnistía argentina- estuvo rodeada de amplios e inclusivos debates públicos, que culminaron en diversas instancias plenamente abiertas a la participación popular. ${ }^{6}$ La teoría de Nino, a

${ }^{5}$ Caso Nibia Sabalsagaray Curutchet, p. 32

${ }^{6}$ El resultado -cabe aclarar y enfatizar este punto- fue, como podía esperarse, especialmente interesante en términos de imparcialidad: no se trató de una amnistía "a secas", en donde una parte de la sociedad simplemente impuso sobre la otra su deseo de olvidar, sino una decisión reflexiva y matizada: Uruguay condenó políticamente lo 
diferencia de lo hecho por la Corte IDH en el fallo Gelman, nos da buenas razones para distinguir y pensar críticamente en torno a ambas amnistías. Nos da razones para impulsar la anulación de la ley de autoamnistía, a la vez que nos permite reconocer por qué la autoamnistía uruguaya es diferente y merece por tanto un tratamiento también diferente.

\section{Grados de validez I: la especial dificultad que afecta a las normas penales}

La autoamnistía militar en la Argentina y la amnistía ratificada popularmente en Uruguay, constituyen dos casos reales, públicamente muy relevantes y a la vez muy distintos, sobre los modos en que se puede pensar y construir el derecho penal. Si miramos dichos casos desde la perspectiva de una teoría deliberativa, como la que defendiera Nino, nos encontramos con que dichos casos se sitúan en polos opuestos, dentro de un continuo. Tal como hemos dicho, la autoamnistía argentina ilustra bien el polo "negativo" de normas creadas sin discusión y a partir de la exclusión. Mientras tanto, la amnistía uruguaya ilustra bien el polo "positivo" de normas discutidas y aprobadas colectivamente. En el medio, esperablemente, nos encontramos con muchas otras "estaciones" o "paradas" posibles, que ameritan una consideración especial, conforme al lugar en el que se sitúen dentro del continuo referido. La aproximación de Nino nos ayuda a reconocer, entender e interpretar esos diferentes matices.

En este sentido, la visión de Nino en torno a los "grados de validez" de las normas, parece retomar y mejorar el acercamiento que fuera propio de un colega suyo de la Universidad de Yale, Bruce Ackerman, quien distinguía entre normas originadas en "momentos corrientes" (propias del funcionamiento normal, anodino, de una democracia de baja intensidad, caracterizada por una muy modesta participación cívica y bajos niveles de discusión colectiva) y normas surgidas en "momentos constitucionales", caracterizados por la presencia de un "pueblo puesto de pie", que debate en las calles, en los periódicos, en los foros políticos y no políticos acerca de algún asunto de interés común (el gran ejemplo de Ackerman, en este respecto, es la discusión que rodeó al surgimiento del New Deal).

Para Ackerman, las normas surgidas en "momentos constitucionales" debían considerarse como iniciativas dotadas de una

ocurrido; hizo declaraciones públicas desde las máximas instancias, en tal sentido; promovió su propio informe "Nunca más;" realizó homenajes, construyó monumentos, realizó ejercicios de memoria; investigó ampliamente lo ocurrido durante los años atroces (Gargarella 2013). 
fortaleza normativa especial. Tanto así, que Ackerman sugería considerar a las mismas como reformas constitucionales de hecho (Ackerman 1993). Frente a Ackerman, Nino consideraba que esa división dual que el norteamericano proponía era en efecto relevante, en tanto nos iluminaba sobre matices que la teoría constitucional contemporánea no nos ayudaba a ver: las teorías dominantes, en efecto, tendían a "aplanar" todo el derecho, considerando que todas las normas aprobadas por el Congreso eran lo mismo: ya sea (en las lecturas "constitucionalistas" habituales) normas sometidas igualmente a la supremacía de la Constitución, ya sea (en las lecturas más "rousseaunianas") normas merecedoras del máximo respeto en tanto expresiones de la más alta soberanía popular. A la vez, Nino criticaba por esquemático el abordaje de Ackerman, que si bien introducía algún input crucial sobre las doctrinas dominantes, no nos permitía todavía reconocer otros matices necesarios: en el mundo real, las normas no se dividen entre normas de rango constitucional y normas corrientes. Existen normas extraordinariamente debatidas (como la amnistía uruguaya); normas muy discutidas (como el divorcio o el matrimonio igualitario en la Argentina); normas aprobadas en sesiones oscuras, en medio de la noche; normas basadas en una drástica exclusión social (como la autoamnistía argentina); etc., etc. ${ }^{7}$

Una vez que contamos con herramientas como las ofrecidas por Nino para la evaluación "democrática" de la validez de las normas, puede tener sentido poner a prueba dicho aparato teórico para evaluar otras normas penales, menos excepcionales, más cotidianas, menos extremas que las ejemplificadas por la amnistía uruguaya y la autoamnistía argentina.

El campo de las normas penales, vale aclararlo, nos ofrece un terreno de análisis particularmente sugerente y relevante. Ello así, porque se trata de un área ávida de una sólida y especial justificación, dadas sus implicaciones coercitivas; un área que, a la vez, y por lo que sabemos, resulta especialmente deficitaria en términos de justificación. En otras palabras, aquí necesitamos, como en pocos otros casos, de normas respaldadas por un amplio proceso de discusión e inclusión, ya que no podemos correr el riesgo de que las más severas formas de la coerción legítima se ejerzan indebidamente. Contra lo que resultaría deseable y exigible, solemos encontrarnos aquí, según diré, demasiado cerca del polo "negativo" marcado por la presencia de normas creadas, aplicadas e interpretadas a través de procesos excluyentes y poco discutidos.

${ }^{7}$ De hecho, puedo dar testimonio de las discusiones entre Nino y Ackerman sobre el punto, en donde Nino le criticara al último su división en "dos momentos", y la necesidad de reconocer la importancia de los matices y los grados de validez. 
Sobre la especial necesidad de justificación del derecho penal no es mucho lo que deba agregar: asumo aquí que el derecho penal versa sobre un área del derecho particularmente sensible y necesitada de justificación. Ello, ya que esta porción del derecho trata acerca del uso de la violencia legítima, por parte de un Estado que se ha arrogado el empleo de la fuerza, incluyendo modos como los del castigo que -siguiendo a $\mathrm{H}$. Hart-nos refieren a la "imposición deliberada de dolor" (Hart 1968). En definitiva, las normas penales requieren de una ultrajustificación, dada la importancia de lo que allí está en juego y los riesgos que el uso de ese monopolio estatal de la violencia implican. Según podría predecir una teoría como la de Nino, en ausencia de una discusión amplia e inclusiva, correríamos el riesgo de que las normas penales resulten creadas y administradas por una elite, en su propio favor, y en contra de sectores sociales que les son ajenos. Sin tomar a este dato impresionista como decisivo, mencionaría al hecho siguiente, en respaldo a la predicción anterior: en sociedades como la nuestra, marcadas por una composición social fuertemente heterogénea, hemos tenido desde nuestra fundación, composiciones carcelarias fuertemente homogéneas. La teoría de Nino, según entiendo, nos ayuda a prever este tipo de resultados. En teorías como las de Nino, en efecto, la discusión inclusiva no es valorada por cuestiones caprichosas, sino porque se entiende que necesitamos del punto de vista de todos -y particularmente de los más afectados-para saber si estamos tomando decisiones justas, respetuosas de las distintas pretensiones sociales en conflicto propias de toda sociedad heterogénea.

En los hechos, y conforme anticipara, la práctica histórica del derecho penal nos sugiere que, contra lo señalado, el derecho penal-que tan especial justificación requiere- se muestra por lo general aislado y resistente frente al debate colectivo inclusivo. En efecto, y según lo que la sociología del derecho penal nos explica, el derecho penal tiende a oscilar en estos tiempos entre el welfarismo penal y el populismo penal. En otros términos, el derecho penal que conocemos puede considerarse como un permanente producto de elites, ya sea elites animadas por propósitos bienestaristas/garantistas, ya sea elites animadas por la búsqueda del endurecimiento de las penas. En ocasiones, dicho elitismo surge de teorías (welfaristas) que invocan, en su respaldo, el resguardo de los intereses de la ciudadanía. En otras ocasiones, dicho elitismo es producto de teorías populistas que invocan, en su respaldo, el respeto de la voluntad de la ciudadanía. En ambos casos, sin embargo, nos encontramos frente a teorías que, a pesar de sus invocaciones, dan la espalda, directamente, a cualquier intento genuino y efectivo de consulta o diálogo con la ciudadanía democrática. Este hecho, bien documentado por sociólogos 
penales como David Garland para el ámbito anglosajón, ha sido bien respaldado por sociólogos penales como Máximo Sozzo (un discípulo de aquel), para ámbitos como el argentino (Garland 2001, cap. 7; Sozzo 2011).

En definitiva, el hecho es que -contra lo que podríamos esperar, y sobre todo exigir- las normas penales que nos rodean aparecen significativamente afectadas en términos de imparcialidad. Así, y por un lado, nos encontramos con déficits en lo que hace al requerimiento de inclusión (en conflicto con el carácter excluyente de los métodos propios del elitismo y el populismo penal), y por otro, nos encontramos con dificultades en lo que concierne al requerimiento del debate público (una exigencia que afecta de modo especial y habitual a las iniciativas populistas).

\section{Grados de validez II: el derecho penal en sociedades desiguales}

Carlos Nino fue muy consciente, según entiendo, de la especial necesidad y la particular dificultad que existe en torno a la justificación de las normas penales. Sobre todo en la segunda etapa -la más "democrática" - de su vida académica, tales preocupaciones resultaron más notorias, aun cuando Nino no encontrara el tiempo o el espacio suficientes para escribir detalladamente sobre ellas. De todas formas, aun así, nos encontramos con algunos artículos de su autoría, bastante explícitos e interesantes, en la materia.

Un texto particularmente relevante en este respecto es el que aparece en 1989 bajo el título "Democracy and the Criminal Law", y que es incluido por Gustavo Maurino en la compilación que edita en el año 2007, en la que reúne textos dispersos publicados por Nino en el área penal. En el artículo citado, Nino sostiene, por ejemplo, que "el origen democrático de ciertas reglas como las leyes penales fundamenta una presunción revocable de que su contenido es justo" (Nino 2007, p. 21). ${ }^{8}$ En el último párrafo de dicho artículo, Nino afirma asimismo que

el origen democrático de las leyes penales afecta profundamente la justificación moral de estas leyes: provee una presunción de que su contenido es justo, lo cual es condición que se combina con otra, como el consentimiento, para la legitimación de su aplicación coercitiva a través de la imposición de castigo y, dada la limitación de esta presunción a las cuestiones de moral intersubjetiva, genera, en

8 Algunas consideraciones aparecen también en su debate con Raúl Zaffaroni, publicado en la revista No hay derecho (Nino 1991). 
combinación con los supuestos liberales, un fuerte escudo contra intrusiones penales sobre la autonomía personal (Nino 2007, p. 24).

Quedan así combinadas, de una forma muy plena, sus intuiciones democráticas por un lado, y por otro sus preocupaciones por el resguardo de la autonomía personal, dentro del área del derecho penal.

Aún cuando Nino no dedicara trabajos sustantivos especiales sobre la materia, resultaba claro, a partir de textos como el citado, que en esta segunda etapa de su vida académica, Nino empezaba a explorar más directamente las implicaciones de su teoría democrática para la justificación de las normas penales. Bastante más que ello: escribiendo desde una sociedad profundamente desigual, como la Argentina, Nino encontró la oportunidad para dejar en claro el punto que aquí más nos interesa enfatizar, referido a las implicaciones de dichas conexiones (entre democracia y derecho penal) para sociedades fuertemente desiguales como la Argentina. Nino sostuvo entonces no solo i) que las normas penales debían originarse democráticamente, y ii) que dicho origen democrático favorecía la presunción de validez de tales normas. Él se ocupó de dejar en claro, también, cuál era la excepción más importante, frente a dicha presunción de validez democrática.

En efecto, en opinión de Nino, la "principal excepción" a dicho principio general (acerca de la presunción de imparcialidad de las normas que son producto de un debate democrático) aparece (obviamente agregaría) "cuando las condiciones básicas que permiten al proceso democrático tener valor epistémico están ausentes: por ejemplo, cuando algunos grupos son impedidos de expresar sus opiniones a través de persecuciones o cuestiones similares”(Nino 2007, p. 21, el énfasis es mío).

El punto refuerza, estructura mejor y ayuda a iluminar otro similar que se derivaba de su peculiar teoría consensual de la pena (teoría que marca desde los inicios de su vida académica su visión sobre la pena): "si no hay una relativa igualdad en las posibilidades de elección de los individuos, no se puede otorgar validez a su consentimiento de asumir una cierta responsabilidad, con el objeto de justificar que se le imponga a él una pena socialmente útil" (Nino 1991, p. 6). Se trata de una cuestión que es crucial para nuestros propósitos, y viene a afirmar algunos de los estudios que hemos hecho sobre el tema y las expectativas que teníamos respecto de las implicaciones de una teoría como la de Nino, aplicada al ámbito penal (cf. Gargarella 2011). Lo que la teoría de Nino nos ayuda a decir, en particular, es que en contextos de grave desigualdad, las normas (penales en este caso) empiezan a perder la presunción de validez de la que pretenden gozar, en tanto normas aprobadas por un Congreso 
democrático. El Estado, correlativamente, empieza a perder autoridad para ejercer su autoridad coercitiva. ${ }^{9}$ Queda en cuestión, de este modo, la autoridad del Estado para utilizar sus poderes coercitivos que, previsiblemente -y como la teoría de Nino nos ayudaba a predecir-van a afectar, fundamentalmente, a los sectores sociales más necesitados de su ayuda; ayuda que el Estado les debe a aquellos en razón de los amplísimos compromisos de rango constitucional que ha asumido hacia los más desaventajados.

Es interesante reconocer, en este punto, que conclusiones como la citada (acerca de la baja presunción de validez de las normas penales creadas en contextos de desigualdad), que Nino apenas sugiere (aunque de modo explícito) en el texto mencionado, parecen propias de una literatura que, de modo más abierto, ha ido tejiendo conexiones entre derecho penal y democracia deliberativa. Pienso, en particular, en las concepciones comunicativas sobre la pena, tales como la que ha desarrollado, de modo bastante excepcional, Antony Duff (Duff 2001, 2004). ${ }^{10}$ Aunque con un acercamiento distinto al de Nino en relación con el castigo, Duff trabajó de modo muy cuidadoso sobre la idea -también sugerida por Nino- conforme a la cual, en condiciones de injusta desigualdad, la fuerza autoritativa del derecho penal se debilita. Para Duff, las teorías comunicativas no solo aparecen particularmente interesadas en la cuestión sobre la autoridad moral del Estado para realizar determinados reproches, sino que además resultan especialmente "iluminadoras" en este sentido (dado el carácter de "ida y vuelta" de estas teorías, que requieren que ponga atención no solo en las acciones del imputado, sino también en las condiciones propias para hacer la impugnación del caso) (Duff 1999, p. 61). Como señalara Duff, el criminal puede reconocerse culpable de una cierta falta, pero aun así preservar una

${ }^{9}$ Entiéndase bien, de todos modos: lo que queda en cuestión no es, simplemente, el mal ejercicio de sus poderes coercitivos. Que el Estado, contemporáneamente, haya convertido a las cárceles en mecanismos cotidianos de tortura solo agrava los hechos del caso.

${ }^{10}$ A diferencia de las visiones expresivas sobre la pena -que justifican al castigo como un modo de expresión pública de reproche hacia el criminal- teorías como las de Duff entienden al castigo como una relación comunicativa, de ida y vuelta (no de "una sola vía"), en relación con el ofensor (Feinberg 1965, Hampton 1984). Por lo demás, teorías comunicativas como la de Duff han explorado de modo muy interesante de qué modo una teoría de la democracia con estos rasgos deliberativos/comunicativos podría intervenir para repensar los aspectos básicos del derecho penal -una exploración que Pablo de Greiff realizara, de modo pionero, tomando como eje directamente el trabajo de Nino (de Greiff 2002). 
"carta ganadora" frente al Estado, expresada en una pregunta como la siguiente: "yo he cometido una falta, sí, pero ¿quién es usted para reprochármela?" (Duff 2004). En condiciones de injusta desigualdad, el Estado, diría Duff, pierde legitimidad moral (moral standing) para ejercer ciertos reproches. En tal tipo de contextos resultan socavadas las precondiciones del reproche estatal (Duff 2001).

Permítanme insistir en la reconstrucción de lo dicho en términos de la teoría democrática de Nino: en situaciones de fuerte exclusión social, es dable esperar que las normas sean el resultado de la creación, aplicación e interpretación de una elite. Esa forma tan imperfecta de generación del derecho (dependiendo, obviamente, de las características del caso concreto) tiende a afectar la validez del mismo. Ello, porque en la medida en que ciertas voces se encuentren sistemáticamente ausentes de tal proceso creativo, y otras resulten indebidamente predominantes en el mismo, el derecho, previsiblemente, va a comenzar a sesgarse. Ya no puede presumirse, entonces, que el derecho va a resultar imparcial respecto de las pretensiones de todos. Por el contrario, lo que puede preverse es que en tales situaciones el derecho va a tender a constituirse en el derecho propio de una elite, creado por una elite, para su propio beneficio. Dicho derecho, por tanto, debe concebirse como situado cerca del extremo negativo del arco delineado por el ideal de la democracia deliberativa -muy cerca del área que Nino considerase como caracterizada por una presunción de validez cercana a cero. En tales situaciones, agrega Duff, es previsible que la voz del derecho comience a resultar para muchos una voz ininteligible, ajena, "una voz extraña que no es ni podría ser de ellos" que abre dudas acerca de que esas personas puedan considerarse como ciudadanos "atados a las leyes". La idea de que ellos "deben responder a la comunidad, se convierte en una idea vacía" (¿en reciprocidad a qué es que los ciudadanos deberían responder a los llamados del Estado?) (Duff 2001, pp. 195-196; Murphy 1973). La presunción de que el Estado, en tales condiciones, tiene el derecho de seguir haciendo uso de su poder más gravoso, pierde fuerza también.

La situación que imaginara Nino, como aquella que describiera Duff en el párrafo recién citado, tiene cierta analogía con la posición en que se encuentra un padre abusador cuando quiere reprochar a su hijo por una falta que este ha cometido (aun reconociendo los problemas obvios que existen para el uso de este tipo de analogías entre familia y Estado). El hijo puede reconocer, frente al padre, que la conducta que ha cometido es incorrecta; como puede reconocer además que él es responsable de haberla cometido. Sin embargo, nada de ello le impide seguir impugnando la autoridad del padre para reprocharle esa inconducta. El hijo puede 
repetir entonces, frente al padre abusador, la misma pregunta en la que Duff pensaba: "yo he cometido una falta, sí, pero ¿quién es usted para reprochármela?"11

Conviene insistir en esto: impugnar la validez de las normas penales creadas en determinados contextos y de determinadas formas, e impugnar por tanto la autoridad penal del Estado para hacer uso de la coerción penal, no implica negar la responsabilidad de un determinado sujeto -pongamos, de clase baja- en la comisión de un determinado crimen. El punto es relevante porque, en las últimas décadas del siglo $\mathrm{XX}$, parte de la doctrina y la jurisprudencia se esforzaron por impugnar la responsabilidad criminal efectiva de las personas nacidas en contextos de extrema vulnerabilidad. Ello, en razón de lo que se denominara "el contexto social de podredumbre" (rotten social background) en el que esas personas habían nacido y crecido. Fue famosa, en tal sentido, la iniciativa avanzada por el juez Bazelon en casos como United States v. Alexander (471 F. 2nd. 923, 957'65 (D.C. Cir. 1973, Bazelon, C.J., disidencia), y desarrollada luego en una serie de artículos académicos, Bazelon 1976a, 1976b, 1988; Delgado 1985)..$^{12}$ De modo nada sorpresivo, esta línea de reflexión generó fuertes resistencias dentro del ámbito penal (Moore 1985, Morse 1976a, 1976b). ${ }^{13}$ Claramente, posturas como las que aquí hemos defendido, de ningún modo nos llevan a renunciar al reconocimiento de la responsabilidad de quienes han cometido una falta. Podemos seguir llamando crimen al crimen, y criminal ha quien lo ha cometido. Pero ello no nos libra de la pregunta

${ }^{11}$ Duff piensa, en verdad, en dos situaciones capaces de socavar el "standing moral" del demandante. La primera, relacionada con mi falta de vínculos apropiados con la persona acusada, o con la acción en cuestión: puede ocurrir, por ejemplo, que dicha persona pueda ser juzgada por otros, pero no por mí porque, digamos, yo no forma parte de la comunidad jurídica relevante para intervenir en el caso. La segunda situación es la que aparece cuando mi "standing moral" resulta socavado en razón de "mis acciones previas" en relación con la persona impugnada (lo que no implica que esto justifique o excuse la acción del caso sino, simplemente, que yo no tenga legitimidad moral para criticarla). Véase, en general, Duff 1999, pp. 61-62.

12 En dicho caso, Bazelon propuso comparar la extrema pobreza con la insania, y propuso tratar a ambas de la misma manera, mitigando radicalmente la responsabilidad criminal de los ofensores del caso.

${ }^{13}$ Autores como Stephen Morse - un abogado y psicólogo- sostuvo que el trabajo de Bazelon era empíricamente equivocado (la mayor parte de los desaventajados tendían a obedecer al derecho), poco persuasivo, además de "impracticable" (Morse 1976a, p. 1251; Bazelon 1976b, p. 1269). Otra crítica crucial contra tales posturas provino de criminólogos como Michael Moore. Para Moore, la postura de Bazelon asumía criterios "elitistas y condescendientes", que terminaban por negar la "igual dignidad moral" de los menos aventajados (Moore 1985). 
fundamental sobre la autoridad que tiene (o no) el Estado para castigar ese crimen.

Finalmente, lo que afirmaría es que cualquier comunidad tiene el derecho de seleccionar conductas públicas (en el ámbito que Nino llamaba de "moral intersubjetiva") que considera impermisibles, y establecer formas particulares para reprocharlas. Pero reprochar $-\mathrm{y}$ hay muchas formas de reprochar- no es lo mismo que castigar (definiendo al castigo en los modos arriba explicitados). El Estado que quiere imponer dolor a través de los medios coercitivos que monopoliza (y, muy en particular, pero no solo, si quiere disponer de la violencia de los modos en que hoy lo hace), asume sobre sí mismo una carga justificativa extraordinaria, que no puede simplemente ignorar o minimizar. Muchísimo menos en situaciones de injusta desigualdad. Teorías democráticas como la de Carlos Nino nos ayudan a reconocer por qué es que las normas penales creadas por una elite, en el marco de sociedades profundamente desiguales, pierden presunción de validez (y así, presunción de constitucionalidad); por qué es que, entonces, las justificaciones que hoy el Estado ofrece a favor de su uso de la coerción no resultan persuasivas; y por qué es que su autoridad termina quedando, en tales condiciones, cuestionada. ${ }^{14} \mathrm{La}$ teoría de la deliberación democrática elaborada, entre otros, por Carlos Nino, sigue contando con una potencia extraordinaria para ayudarnos a pensar en temas cruciales sobre el derecho penal y el castigo.

\section{Bibliografía}

Ackerman, B. (1993), We the People: Foundations, Nueva York, Belknap Press.

Bazelon, D. (1976a), "The Morality of the Criminal Law", Southern California Law Review, 49, pp. 385-405.

(1976b) "The Morality of the Criminal Law: A Rejoinder to Professor Morse", Southern California Law Review, 49, p. 1269. (1988), Questioning Authority: Justice and the Criminal Law, Nueva York, Alfred Knopf.

Bohman, J. (1996), Public Deliberation: Pluralism, Complexity, and Democracy, Cambridge, The MIT Press.

Braithwaite, J. y Pettit, P. (1990), Not Just Deserts: A Republican Theory of Criminal Law, Oxford, Clarendon Press.

${ }^{14}$ Las razones prudenciales, instrumentales, que puedan existir para preservar la paz social, no pueden reemplazar en dicho contexto las razones que son necesarias que el Estado dé, para ganar autoridad para castigar. 
De Greiff, P. (2002), "Deliberative Democracy and Punishment”, Buffalo Criminal Law Review, 5(2), pp. 373-403.

Delgado, R. (1985), "Rotten Social Background: Should the Criminal Law Recognize a Defense of Severe Environmental Deprivation?", Law and Inequality, 3, pp. 9-90.

Duff, A. (1999), "Punishment, Communication and Community," en Mattravers, M. (ed.), Punishment and Political Theory, Oxford, Hart Publishing.

(2001), Punishment, Communication and Community, Oxford, Oxford University Press.

(2004), "I Might be Guilty, but You Can't Try Me: Estoppel and Other Bars to Trial", Ohio St. J. Crim. L., 245.

Duff, A. y Garland, D. (1994), A Reader on Punishment, Oxford, Oxford University Press.

Elster, J. (ed.) (1998), Deliberative Democracy, Cambridge, Cambridge University Press.

Feinberg, J. (1965), "The Expressive Function of Punishment", The Monist, 49, pp. 397-423.

Ferrajoli, L. (2008), Democracia y garantismo, Madrid, Trotta.

Gargarella, R. (2005), Derecho a protestar: El primer derecho, Buenos Aires, Ad Hoc.

(2009), "Though on Punishment: Criminal Justice, Deliberation and Legal Alienation", en Besson, S. y Martí, J. L. (eds.), Legal Republicanism, Oxford, Oxford University Press, pp. 167-186.

(2010), "Cuatro temas y cuatro problemas en la teoría jurídica de Luigi Ferrajoli”, en Revista de Derecho Penal y Procesal Penal, 2, Buenos Aires, Abeledo Perrot, pp. 199-207.

(2011), "Penal Coercion in Contexts of Social Injustice", Criminal Law and Philosophy, 5(1), pp. 21-38.

(2013), "Sin lugar para la soberanía popular: Democracia, derechos y castigo en el caso Gelman". Disponible en http://www.law.yale.edu/documents/pdf/sela/SELA13_Gargarella_C V_Sp_20120924.pdf

Garland, D. (2001), The Culture of Control-Crime and Social Order in Contemporary Society, Oxford, Oxford University Press.

Habermas, J. (1996), Between Facts and Norms, Cambridge, The MIT Press. (Traducción al inglés de Faktizität und Geltung, 1992.)

Hampton, J. (1984), "The Moral Education Theory of Punishment", Philosophy and Public Affairs, 13(3), pp. 208-238.

Hart, H. (1968), "Prolegomenon to the Principles of Punishment," en Punishment and Responsibility, Oxford, Oxford University Press. 
Moore, M. (1985), "Causation and the Excuses", California Law Review, 73(4), pp. 1091-1149.

Morse, S. (1976a), "The Twilight of Welfare Criminology: A Reply to Judge Bazelon", Southern California Law Review, 49, p. 1247.

— (1976b), "The Twilight of Welfare Criminology: A Final Word", Southern California Law Review, 49, p. 1275.

Murphy, J. (1973), "Marxism and Retribution", Philosophy and Public Affairs, 2, pp. 217-243.

Nino, C. S. (1980), Los limites de la responsabilidad penal, Buenos Aires, Astrea.

— (1982), La legítima defensa, Buenos Aires, Astrea.

_ (1983a), "Hacia una nueva estrategia para el tratamiento de las normas de facto," La Ley 1983-D, p. 935.

- (1983b), "A Consensual Theory of Punishment", Philosophy and Public Affairs, 12, pp. 289-306

- (1984), Ética y derechos humanos, Buenos Aires, Astrea (Traducción al inglés: The Ethics of Human Rights, Oxford, Oxford University Press, 1991).

(1985), La validez del derecho, Buenos Aires, Astrea.

(1986), "Does Consent Override Proportionality", Philosophy and Public Affairs, 15(2), pp. 183-187.

_ (1991), "Debate con Eugenio Raúl Zaffaroni”, No hay derecho, II(4), pp. 4-8.

— (1992), Fundamentos de derecho constitucional, Buenos Aires, Astrea.

(1993), Radical Evil on Trial, New Haven, Yale University Press. (1994), Derecho, moral y política, Barcelona, Ariel.

(1996), The Constitution of Deliberative Democracy, New Haven, Yale University Press.

(2007), Fundamentos de derecho penal, Buenos Aires, Gedisa.

(2013), Una teoría de la justicia para la democracia, Buenos Aires, Siglo XXI.

Sozzo, M. (2011), "Transition to Democracy and Penal Policy: The case of Argentina”, Straus Working Paper 03/11, New York University.

Recibido el 2 de septiembre de 2014; aceptado el 15 de noviembre de 2014. 